\title{
Frontal white matter lesions in Alzheimer's disease are associated with both small vessel disease and AD-associated cortical pathology
}

\author{
Kirsty E. McAleese ${ }^{1}$ (1) Mohi Miah ${ }^{1} \cdot$ Sophie Graham ${ }^{1} \cdot$ Georgina M. Hadfield $^{1} \cdot$ Lauren Walker $^{1} \cdot$ Mary Johnson $^{1}$. \\ Sean J. Colloby ${ }^{1} \cdot$ Alan J. Thomas $^{1} \cdot$ Charles DeCarli $^{2} \cdot$ David Koss $^{1} \cdot$ Johannes Attems ${ }^{1}$
}

Received: 24 April 2021 / Revised: 26 September 2021 / Accepted: 27 September 2021 / Published online: 4 October 2021

(c) Crown 2021

\begin{abstract}
Cerebral white matter lesions (WML) encompass axonal loss and demyelination and are assumed to be associated with small vessel disease (SVD)-related ischaemia. However, our previous study in the parietal lobe white matter revealed that WML in Alzheimer's disease (AD) are linked with degenerative axonal loss secondary to the deposition of cortical AD pathology. Furthermore, neuroimaging data suggest that pathomechanisms for the development of WML differ between anterior and posterior lobes with $\mathrm{AD}$-associated degenerative mechanism driving posterior white matter disruption, and both AD-associated degenerative and vascular mechanisms contributed to anterior matter disruption. In this pilot study, we used human post-mortem brain tissue to investigate the composition and aetiology of frontal WML from AD and non-demented controls to determine if frontal WML are SVD-associated and to reveal any regional differences in the pathogenesis of WML. Frontal WML tissue sections from 40 human post-mortem brains (AD, $n=19$; controls, $n=21$ ) were quantitatively assessed for demyelination, axonal loss, cortical hyperphosphorylated tau (HP $\tau)$ and amyloid-beta $(\mathrm{A} \beta)$ burden, and arteriolosclerosis as a measure of SVD. Biochemical assessment included Wallerian degeneration-associated protease calpain and the myelin-associated glycoprotein to proteolipid protein ratio as a measure of ante-mortem ischaemia. Arteriolosclerosis severity was found to be associated with and a significant predictor of frontal WML severity in both AD and non-demented controls. Interesting, frontal axonal loss was also associated with $\mathrm{HP} \tau$ and calpain levels were associated with increasing $\mathrm{A} \beta$ burden in the $\mathrm{AD}$ group, suggestive of an additional degenerative influence. To conclude, this pilot data suggest that frontal WML in AD may result from both increased arteriolosclerosis and AD-associated degenerative changes. These preliminary findings in combination with previously published data tentatively indicate regional differences in the aetiology of WML in $\mathrm{AD}$, which should be considered in the clinical diagnosis of dementia subtypes: posterior WML maybe associated with degenerative mechanisms secondary to AD pathology, while anterior WML could be associated with both SVD-associated and degenerative mechanisms.
\end{abstract}

Keywords White matter lesion $\cdot$ White matter hyperintensity $\cdot$ Alzheimer's disease $\cdot$ Small vessel disease $\cdot$ Amyloid-beta . Hyperphosphorylated tau

\begin{tabular}{|c|c|c|c|}
\hline \multicolumn{2}{|c|}{ Abbreviations } & CVD & Cardiovascular disease \\
\hline $\mathrm{AD}$ & Alzheimer's disease & CVRF & Cardiovascular risk factor \\
\hline $\mathrm{A} \beta$ & Amyloid-beta & DTI & Diffusion tensor imaging \\
\hline $\mathrm{BiA}$ & Bielschowsky's \% area & ELISA & Enzyme-linked immunosorbent sandwich assays \\
\hline CAA & Cerebral amyloid angiopathy & $\mathrm{HP} \tau$ & Hyperphosphorylated tau \\
\hline \multirow[t]{2}{*}{$\mathrm{CC}$} & Corpus callosum & IOD & Integrated optical density \\
\hline & & IR & Immunoreactivity \\
\hline \multirow[t]{3}{*}{$\triangle$} & E. McAleese & LFB & Luxol fast blue \\
\hline & McAleese@ncl.ac.uk & MAG & Myelin-associated glycoprotein \\
\hline & & NAWM & Normal appearing white matter \\
\hline \multirow{2}{*}{$\begin{array}{l}\mathrm{T} \\
\mathrm{U}\end{array}$} & lation and Clinical Research Institute, Newcastle & PLP & Proteolipid protein \\
\hline & rsity, Newcastle upon Tyne NE4 SPL, UK & RBG & Red, blue, green (threshold) \\
\hline ( & tment of Neurology, University of California, Davis, & SI & Sclerotic Index \\
\hline
\end{tabular}


SVD Small vessel disease

WMH White matter hyperintensity

WML White matter lesion

WMLA White matter lesion \% area

\section{Introduction}

Cerebral white matter lesions (WML) histologically encompass rarefaction of the cerebral white matter, primarily presenting as demyelination with/without axonal loss with associated oedema and reactive gliosis [17]. During life, white matter changes are detected radiologically as white matter hyperintensities (WMH) on T2-weighted magnetic resonance imaging (MRI) [19] or as altered diffusivity on diffusion tensor imaging (DTI) [6], although it important to note that the presence of a WMH cannot inform us of the underlying causative pathology. WML/WMH are highly associated with age [46], and are commonly seen in individuals with and without dementia [47] presumed to reflect chronic ischaemia-associated demyelination and axonal loss due to arteriopathy of the perforating white matter arteries and arterioles, i.e., type 1 arteriolosclerosis cerebral small vessel disease (SVD) [41, 42]. SVD itself is heterogeneous incorporating atherosclerosis, lipohyalinosis, arteriolosclerosis, blood-brain barrier (BBB) breakdown, fibroid necrosis, and calcification of the perforating arteries and/or arterioles. The presence of WMH is often interpreted as a surrogate marker for SVD [13, 15]. Furthermore, cerebral amyloid angiopathy (CAA), characterized by the accumulation of amyloid-beta (A $\beta$ ) pathology in leptomeningeal, cortical, and capillary vessel walls (Type 2 cerebral SVD [42]), has been shown to be associated with white matter disruption and increased WMH volume $[1,31]$ as well as increased demyelination of associated white matter [53].

WMH are more frequent and severe in Alzheimer's disease (AD) compared to other neurodegenerative diseases and normal ageing $[4,29,58]$ with increased WMH volume contributing to the progression and severity of the clinical syndrome $[9,38]$. The pathogenesis of WML/ $\mathrm{WMH}$ in $\mathrm{AD}$ is complex and poorly understood, incorporating multiple aspects of the neurovascular unit, neurodegeneration, neuroinflammation, and vascular risk factors $[39,45]$ as well as vascular changes. Pioneering neuropathological studies in $\mathrm{AD}$ and non-AD tissue first indicated that WM changes in AD may result from both ischaemia, particularly in the frontal region [14], or from secondary axonal degeneration associated with AD pathology in the overlying cortex, particularly the temporal and parietal regions $[10,26]$. Following on, numerous neuroimaging and neuropathological studies $[1,21,25,29$, $30,48]$ have suggested that WMH in the medial-temporal lobe and posterior regions of the brain can also occur as a result of degenerative white matter changes attributed to the deposition of cortical AD pathology, i.e., hyperphosphorylated tau (HP $\tau)$ and $\mathrm{A} \beta$. We previously performed a comprehensive quantitative neuropathological investigation of the composition and pathogenesis of WML in parietal white matter from individuals clinico-pathological confirmed as $\mathrm{AD}$, as well as age-matched non-demented controls [30]. We revealed that pathological WML in AD are associated with both axonal loss and demyelination, in contrast to non-demented individuals which were primarily associated with demyelination only, and severity of WML are associated with HP $\tau$ deposition. Furthermore, we biochemically measured the Wallerian degenerationspecific protease calpain that is thought to be activated by AD pathology-related axonal transport dysfunction and is associated with the retrograde degradation of axonal cytoskeletal proteins $[12,28]$. Analysis revealed that calpain was significantly higher in WML tissue of AD cases and was associated with AD pathology burden in the overlying cortex. Overall, this previous study indicated that in the parietal white matter of AD cases, WML can result as a consequence of degenerative axonal loss secondary to AD pathology in addition to SVD-associated white matter changes, in agreement with the neuroimaging studies. The findings of our study were confirmed by subsequent post-mortem studies from other groups; Kantarci et al. [21] revealed that Braak NFT staging of $\mathrm{HP} \tau$ was associated with ante-mortem DTI alterations in parietal white matter and medial-temporal lobe connections, and Alosco et al. [1] revealed ante-mortem WMH volume increased the odds of having a higher degree of AD-related pathology at autopsy. In addition, ante-mortem imaging has indicated that tau PET $\left(\left[{ }^{18} \mathrm{~F}\right] \mathrm{AV}-1451\right)$ was associated with DTI changes in the anterior temporal region and tau pathology independently contributed to WM changes [51].

Efforts are now focused on investigating regional differences in the aetiology of WML. The frontal white matter region has been shown to be particularly sensitive to cardiovascular risk factors (CVRF) with increased frontal WMH volume associated with CVRF of middle age [44]. In addition, due to the topographical rostral progression of HP $\tau$ pathology from the entorhinal/limbic regions to the neocortex, the frontal region is affected in the rather late stages of $\mathrm{AD}$ progression, and therefore, in early stages of the disease the frontal white matter, theoretically is less likely to develop degenerative axonal loss compared to the posterior white matter. A pivotal DTI study by Lee et al. further investigated the rostral-caudal gradient of WMH within the corpus callosum (CC) [25]; data from this study indicate that both $\mathrm{AD}$-associated degenerative mechanisms and vascular processes contributed to white matter disruption within the anterior $\mathrm{CC}$, in contrast to disruption in the posterior $\mathrm{CC}$ that was primarily driven by $\mathrm{AD}$-associated degeneration. The 
prominent influence of $\mathrm{AD}$-associated degenerative mechanism in the posterior regions is in agreement with our previous findings from the parietal white matter [30].

It is yet to be determined in human tissue if the pathogenesis of frontal WML is primarily associated with vascular processes, i.e., SVD and CAA, AD-associated degenerative axonal loss, or a mixture of both. Therefore, in this pilot study, we aimed to identify differences in the composition and aetiology of WML in the frontal lobe of AD and non-demented controls using pathological and biochemical methods. Based on our previous neuropathological study and indications from previous imaging studies, we hypothesise that both pathological measures of SVD and HP $\tau$ pathology and biochemical measures of ischaemia and axonal degeneration are associated with and predictors of frontal WML severity and pathological changes, i.e., axonal loss and demyelination.

\section{Methods}

Our study cohort consisted of 40 consecutive donated human post-mortem brains (mean age $84.7 \pm 4.9$ years; male: 16 , female: 24) which were recruited through tertiary research centers or memory clinics. This cohort was based on a subset of cases from the same cohort previously used to investigate parietal WML [30] and cases were subdivided based on the clinico-pathological diagnosis. The known causes of death are listed in Supplementary table 1. During life, all dementia subjects and 18/21 (85.7\%) of the non-demented control subjects underwent prospective clinical assessments by boardcertified Old Age Psychiatrists or Neurologists. All cases had a clinical review of previous psychiatric assessment, as well as a collateral interview to determine cognitive status and the reading of medical records if clinical information for non-demented controls was required after death at Newcastle Brain Tissue Resource (AJT). Non-demented control subjects were confirmed as having showed no evidence of cognitive impairment and had normal everyday functioning up until death. AD cases were confirmed as having a clinical dementia due to AD using the NIA-AA criteria $[33,34]$. Brain tissue was obtained at autopsy and stored within the Newcastle Brain Tissue Resource in accordance with Newcastle University Ethics Board (The Joint Ethics Committee of Newcastle and North Tyneside Health Authority, reference: 08/H0906/136). After autopsy, the left hemisphere, brainstem, and cerebellum were dissected in coronal planes approximately $0.7 \mathrm{~cm}$ intervals and snap frozen between copper plates at $-120{ }^{\circ} \mathrm{C}$ and stored at $-80{ }^{\circ} \mathrm{C}$. The right hemisphere, brainstem, and cerebellum were immersion fixed in $10 \%$ buffered aqueous formaldehyde solution for 4 weeks and then subsequently dissected in coronal planes approximately $0.7 \mathrm{~cm}$ intervals and paraffin-embedded. All brains underwent neuropathological assessment according to the National Institute on Ageing-Alzheimer's Association (NIA-AA) criteria [36], inclusive of Thal phases of $A \beta$ deposition [52], Braak staging of neurofibrillary pathology [8], and Consortium to Establish a Registry for Alzheimer's Disease scoring [35]. Additional neuropathological scoring of Lewy body pathology [7, 32], vascular pathology contribution to cognitive impairment (vascular impairment neuropathological guidelines (VCING); this was inclusive of semi-quantitate assessment of SVD and WML) [49], TDP43 inclusions for the assessment of limbic-predominant agerelated TDP-43 encephalopathy neuropathological change (i.e., LATE-NC) [20] and CAA [40] was performed. Cases did not contain any large infarcts $(>1 \mathrm{~cm})$ or cerebral hemorrhages. The final clinico-pathological diagnosis was AD in 19 cases and non-demented controls in 21 cases. Of note, SVD and other vascular pathologies and/or lesions maybe present in the AD cases, but it did not fill the neuropathological criteria (severe level) to be deemed a mixed dementia in which both the AD and SVD/vascular pathology could independently lead to clinical dementia. Examples of normal appearing white matter, a WML, and SVD pathology are presented in Fig. 1.

\section{Histological procedures}

Paraffin-embedded serial sections from pre-frontal blocks (Brodmann area 9) were cut at $6 \mu \mathrm{m}$ thickness and mounted onto superfrost plus charged glass slides (Thermo Shandon, Cheshire, UK). These sections of tissue primarily contained juxtacortical and deep white matter. Any residual periventricular white matter was excluded from analysis. Sections underwent histological staining with Bielschowsky silver stain (cold method) [27] for assessment of axonal density, myelin stain luxol fast blue (LFB) to assess WML area and demyelination and haematoxylin and eosin $(\mathrm{H} \& \mathrm{E})$ for visualisation of white matter artery/arteriole walls for assessment of SVD. Immunohistochemistry was performed for HP $\tau$ (antibody AT8: pSer199/202/thr205; Innogenetics, Belgium: mouse monoclonal; 1:4000) and A $\beta$ peptide (antibody 4G8: Amyloid 17-24; Signet Labs, Dedham, MA, USA: mouse monoclonal; 1:15,000). Prior to immunostaining, antigen retrieval was performed by microwaving slides in $0.01 \mathrm{~mL}$ citrate buffer for $10 \mathrm{~min}$ for AT8 and immersion in concentrated formic acid for $1 \mathrm{~h}$ for 4G8. Immunopositivity was detected using the Menarini X-Cell-Plus HRP Detection Kit (Menarini Diagnostics, Winnersh-Wokingham, UK) with 3,3 diaminobezidine (i.e., DAB) as a chromagen and haematoxylin as a counter stain. All histologically and immunohistochemically stained sections were subsequently dehydrated through a 

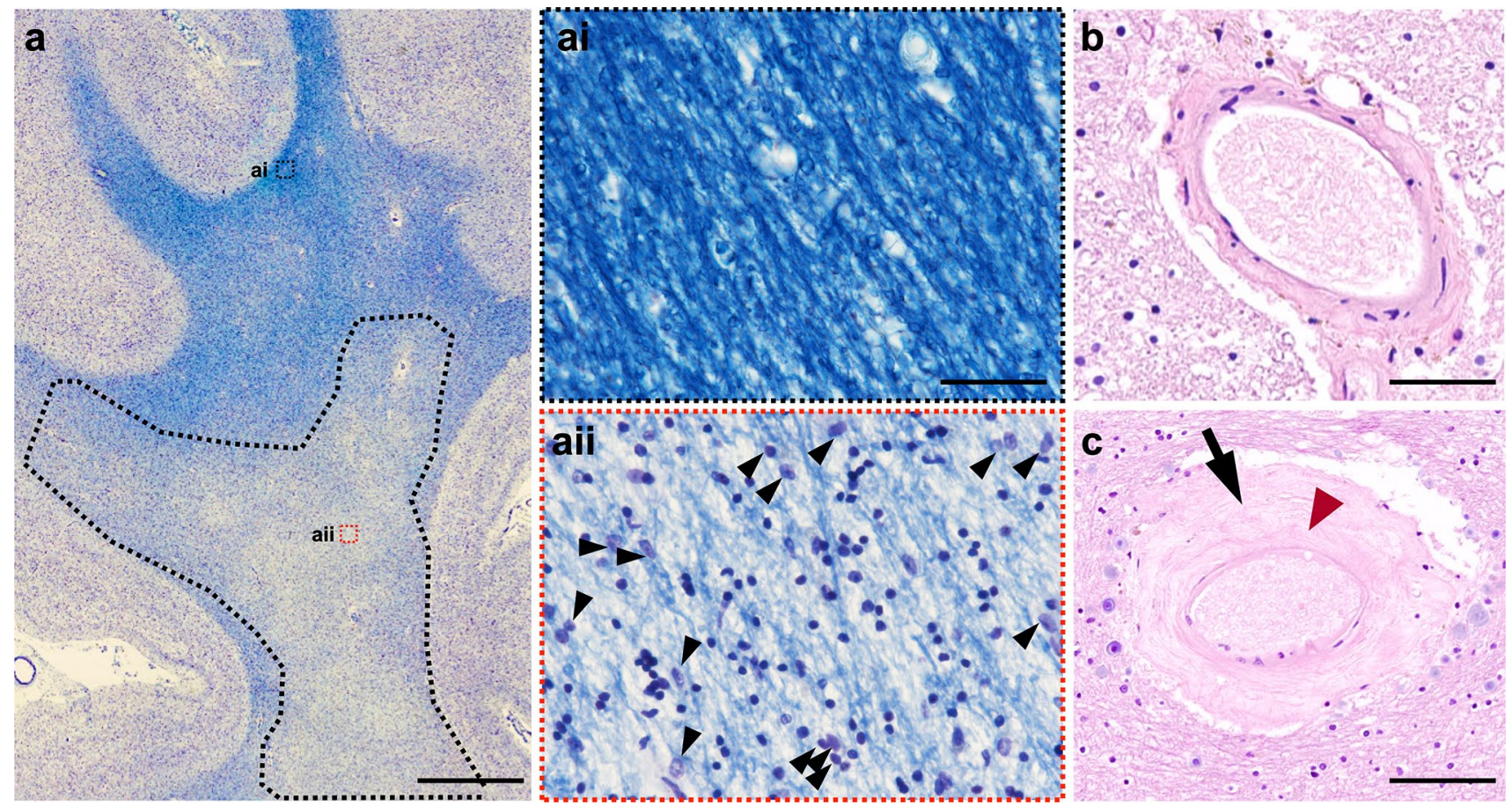

Fig. 1 a LFB and hematoxylin-stained section of frontal lobe tissue illustrating a white matter lesion in the deep white matter (black dashed line; note pallor). (ai) Magnified photoimage of normal appearing white matter; (aii) magnified image of white matter lesion area showing rarefaction of tissue and associated gliosis (black arrow heads); b normal white matter arteriole; $\mathbf{c}$ white matter arteriole with severe arteriolosclerosis exhibiting vessel wall hyalinosis (black arrow) and complete loss of smooth muscle cells (red arrowhead). LFB, luxol fast blue; SVD, small vessel disease; Scale bar, $0.5 \mathrm{~cm}$ valid for image a; $20 \mu \mathrm{m}$ valid for ai and aii; $50 \mu \mathrm{m}$ valid for image $\mathbf{b}$; $100 \mu \mathrm{m}$ valid for image $\mathbf{c}$ series of alcohols, and cleared and mounted using DPX (CellPath, Powys, UK).

\section{Image analysis}

\section{White matter lesion area and demyelination}

All image analysis protocols are described in detail in [30]. All image analysis was performed blind to clinical diagnosis. Briefly, all whole LFB sections were scanned using an Epson Perfection V700 scanner and monochrome images (8-bit grey scale) uploaded into Image-Pro Plus software program (Media Cybernetics Inc, USA; version 6.3). White matter area was manually delineated from the cortical ribbon using the freehand selection tool and total white matter area recorded. The WML area was identified by eye based on a defined reduction in grey colour that is clearly differentiated from the surrounding normal appearing white matter (NAWM), and was confirmed by microscopic examination by the identification of white matter pallor, vacuolation, loosening of tissue, and gliosis [50]. To quantify the WML area from the normal appearing white matter (NAWM), the 8-bit grey scale threshold was manually adjusted to select only the WML area. The percentage area of WML per total white matter area was calculated and expressed as percentage WML area (WMLA) to obtain a measure of overall WML severity. The integrated optical density (IOD) of the LFB stain was determined as a measure of demyelination. The IOD represents the amount of light transmitted through a sample, and therefore, a higher value signifies a greater amount of light transmission, i.e., a lighter stain and a reduction of myelin. Three images from the WML and three images from the NAWM were randomly captured at $200 \times$ magnification using a Nikon 90i microscope and uploaded on Image-Pro Plus. The mean IOD per pixel was recorded for each image and a subsequent mean IOD per pixel for WML and NAWM per case were calculated.

\section{Axonal density}

Once a WML was identified on an LFB section, the WML area was roughly delineated by hand using a permanent marker and was used to identify the same corresponding WML area in the adjacent Bielschowsky stained section. Within the WML area and NAWM on the Bielschowsky section, five randomly selected areas had $3 \times 3$ single images at $200 \times$ magnification which were captured and using NIS elements version 3.0 (Nikon, Surrey, UK). Individual and 
standardized Red Green Blue (RGB) thresholds for Bielschowsky's staining were applied until all visible axons were included with necessary manual setting of regions of interest to exclude vessels and perivascular spaces and artifacts. The area covered by Bielschowsky's stain was measured and its percentage of the total measured area is calculated and expressed as Bielschowsky's area (BiA), and mean regional values were calculated for the WML area and NAWM per case.

\section{Quantification of HPt and A $\beta$ pathology}

$3 \times 3$ single images were captured at $200 \times$ magnification in three frontal cortex sample areas inclusive of the sulci, mid-cortical ribbon, and gyri. Standardized Red Blue Green (RGB) thresholds were applied separately for AT8 and 4G8 RGB intensity values for binary layer pixels were set as follows: AT8: R25-170, G27-156, B11-126; 4G8: R50-180, G20-168, and B8-139. In addition, we set a size restriction threshold for the assessment of 4G8, which excluded the measurement of immunoreactive signals with an area below $100 \mu \mathrm{m}^{2}$; this was necessary to ensure that physiological APP that is stained with 4G8 antibody was not included in the measurement. The percentage areas covered by AT8 and 4G8 immunoreactivity were measured and the mean values for the four sample areas were calculated and are expressed as AT8-IR and 4G8-IR, respectively (Fig. 2).

\section{Quantification of SVD}

Sclerotic index (SI) is a quantitative measure of arteriolosclerosis in the context of SVD. In this study, SI assessment was restricted to white matter arteries and arterioles only. SI is calculated using the formula $\mathrm{SI}=1$ - (internal diameter/ external diameter); the SI of normal arteries and arterioles ranges from 0.2 to 0.3 , while an SI of $0.3-0.5$ indicates mildto-moderate SVD and SI values $>0.5$ are seen in severe SVD [23]. Using H\&E sections, a maximum of eight randomly selected cerebral white matter arteries and/or arterioles were identified, and a single image captured at $200 \times$ magnification. Images were uploaded to the software program VasCalc [56] and SI per vessel calculated followed by the calculation of a mean SI value per case.

\section{Biochemistry}

All protocols are described in detail in [30]. Briefly, $10 \mu \mathrm{m}$ frozen sections inclusive of white matter from Brodmann area 9 were cut, fixed and histochemically stained with LFB to visualise any WML present; this was then used to guide frozen tissue extraction of approximately $250 \mathrm{mg}$ of WML tissue and approximately $250 \mathrm{mg}$ of NAWM tissue from the frozen coronal slab incorporating Brodmann area 9. Lysis buffer contained $0.2 \mathrm{M}$ tetraethyl ammonium bicarbonate, pH 7.2 (i.e., TEAB; Sigma, UK), protease inhibitor tablets (1 tablet per $10 \mathrm{ml}$; Complete, Roche, Burgess Hill, UK) and PhosSTOP, phosphatase inhibitor
Fig. 2 a $3 \times 3$ large image acquisition of frontal cortical AT8-IR (HP $\tau$ pathology). (ai) Image A with applied bespoke AT8-IR threshold (red outline). b $3 \times 3$ large image acquisition of frontal cortical 4G8-IR (A $\beta$ pathology). (bi) Image b with applied bespoke 4G8-IR threshold (red outline) inclusive of size restriction to eliminate the measurement of physiological cellular APP (black arrows). Mean area covered by IR was stated as a percentage of the total image area and the respective values are expressed as AT8-IR or 4G8-IR. IR, immunoreactivity. Scale bar, $100 \mu \mathrm{m}$ valid for all images
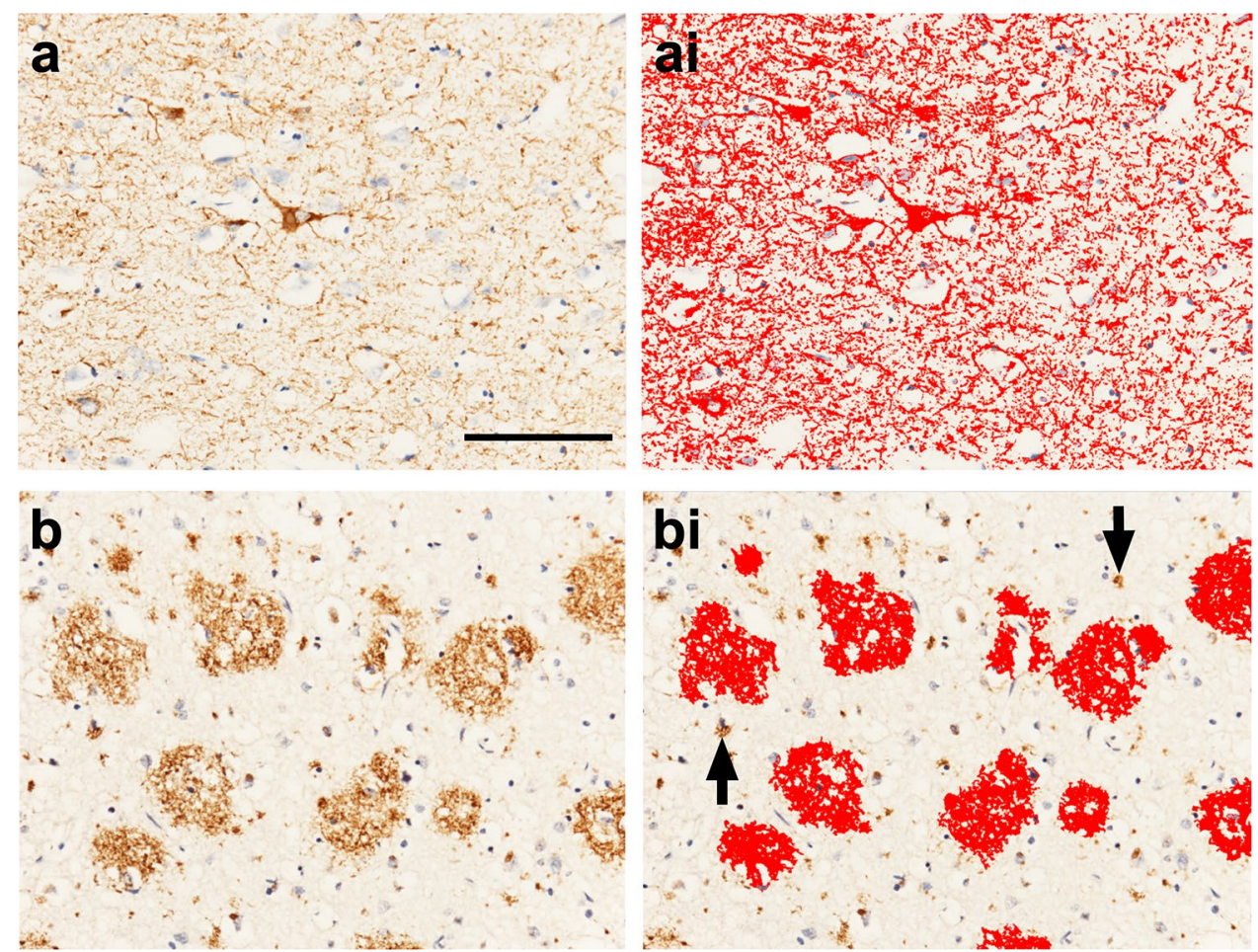
tablets ( 1 tablet per $10 \mathrm{ml}$, Roche) were added to tissue samples at a $1 \mathrm{mg} / 1 \mathrm{ml}$ ratio and samples were homogenised using an Ultra-turrax T10 homogeniser (S10N-5G $5 \mathrm{~mm}$-diameter probe; 30,000 rpm), aliquoted at $500 \mu \mathrm{l}$ with $5 \mu \mathrm{l}$ of $10 \%$ SDS. Total protein concentration was determined by Bradford assay and final protein concentration for all samples was adjusted to $3 \mathrm{ug} / \mathrm{ul}$. Using commercially available enzyme-linked immunosorbent sandwich assays (ELISA) kits, three proteins were measured in both WML and NAWM tissue samples, including Wallerian degeneration markers calpain2 (CAPN2; large catalytic subunit ( $80 \mathrm{kDa}$ ) found in myelinated axons), and ischaemia markers myelin-associated glycoprotein (MAG; myelin sheath protein, expressed only in the myelin loops and highly vulnerable under ischaemic conditions) and proteolipid protein (PLP; myelin sheath protein that is abundant throughout the sheath and stable under ischaemic conditions) [5] to calculate the MAG:PLP as an indication of pre-mortem WM ischaemia [5]. Details regarding ELISA kits are presented in Table 1. ELISA protocols were followed according to manufacturer's instructions as previously described [30].

\section{Statistics}

The Statistical Package for Social Sciences software (SPSS ver. 27) was used for statistical evaluation. Variables were tested for normality using the Shapiro-Wilk test and visual inspection of variable histograms. Differences in related variables (WML vs. NAWM) were assessed using a parametric paired t test or non-parametric Wilcoxon test. Group effects were assessed using either parametric (independent samples $t$ test) or non-parametric (Mann-Whitney $U)$ procedures. Where appropriate, Pearson's $(r)$ or Spearman's $(\rho)$ correlation coefficients, including pairwise deletion, were used to assess associations between variables. Relationships between categorical variables were explored using a $\chi^{2}$. Stepwise linear regression analyses, inclusive of pairwise deletion and collinearity diagnostics (inclusive of variance inflation factor (VIF), were also conducted to investigate if independent pathological variables of SVD, AD pathology, or CAA are predictors of dependent variables of WML severity, axonal loss and demyelination, ischaemia, or Wallerian degeneration. Statistical threshold for significance was set to $p<0.05$.

\section{Results}

\section{Inter- and intragroup comparisons}

No significant differences were observed in age $(p=0.470)$ or post-mortem delay ( $p=0.789$ ) between AD and control groups. Age was not associated with WMLA, BiA (axonal density), LFB-IOD (i.e., demyelination), SI (i.e., arteriolosclerosis severity), CAA, AT8-IR (HP $\tau$ ), or 4G8-IR (i.e., $\mathrm{A} \beta$ ) (all $p>0.072$ ). All 40 cases underwent NAWM assessment and 29 cases (16 AD; 13 controls) exhibited at least one WML. AD cases had significantly higher levels of both semi-quantitative and quantified levels of AD neuropathology (all $p<0.0001)$, CAA severity $(p=0.001)$ compared to non-demented controls. No differences in SI values, WMLA, or NAWM/WML measures of BiA or LFB-IOD were revealed between AD and controls $(p>0.329)$ (all data are presented in Table 2).

Intragroup comparisons of whole cohort and separate $\mathrm{AD}$ and control NAWM and WML tissue measures indicated that WML tissue had significantly lower BiA (all $p<0.0001$ ) and significantly higher LFB-IOD values (all $p<0.05$ ) compared to NAWM, indicating higher levels of axonal loss and demyelination in the WML area as expected.

\section{Cardiovascular risk factors}

Recorded CVRF including presence of hypertension, diabetes, cardiovascular disease and smoking status, as well as final MMSE scores are presented in Supplementary table 1. Employing $\chi^{2}$ test adjusted for age, the presence of hypertension was not significantly associated with semiquantitatively assessed SVD score in either AD $(p=0.333)$ or the control group $(p=0.259)$ nor with semi-quantitatively assessed WML (AD, $p=0.634$; controls $p=0.625)$.

Table 1 ELISA kits used for detection of calpain2, MAG and PLP proteins

\begin{tabular}{|c|c|c|c|c|c|}
\hline \multirow[t]{2}{*}{ Protein } & \multicolumn{2}{|l|}{ ELISA kit } & \multirow[t]{2}{*}{ Sample dilution } & \multirow{2}{*}{$\begin{array}{l}\text { Standard curve } \\
(\mathrm{ng} / \mathrm{ml})\end{array}$} & \multirow[t]{2}{*}{ OD wavelength } \\
\hline & Cat \# & Description & & & \\
\hline CAPN2 & CSB-E17822h & Human CAPN2 ELISA kit, Cusabio & Neat samples & $2.5-0.039$ & 450 and $540 \mathrm{~nm}$ \\
\hline MAG & CSB-E17901h & Human MAG ELISA Kit, Cusabio & Neat samples & $20-0.1$ & 450 and $540 \mathrm{~nm}$ \\
\hline PLP & MBS266920 & Human PLP ELISA Kit, MyBioSource & Neat samples & $10-0.156$ & $450 \mathrm{~nm}$ \\
\hline
\end{tabular}

$C A P N 2$, calpain2; $M A G$, myelin-associated glycoprotein; $P L P$, proteolipid protein 
Table 2 Demographic and neuropathological characteristics of study cohort

\begin{tabular}{|c|c|c|c|}
\hline & $\mathrm{AD}$ & Control & Statistic $_{(d f)}, p$ value \\
\hline Cohort number & 19 & 21 & \\
\hline Mean age, years $( \pm S D)$ & $84.68(4.87)$ & $86.19(7.70)$ & $t_{(38)}=0.731, p=0.470$ \\
\hline Gender and mean age, years $( \pm S D)$ & $\begin{array}{l}\text { Male, } n=6 ; 85.33(5.35) \\
\text { Female, } n=13 ; 84.39(4.82)\end{array}$ & $\begin{array}{l}\text { Male, } n=10 ; 83.15(5.94) \\
\text { Female, } n=11 ; 89.09(8.92)\end{array}$ & $\mathrm{M}: \mathrm{F} ;$ Fischer's $\mathrm{s}_{(1)}, p=0.239$ \\
\hline Mean PMD, hours $( \pm$ SD) & $54.07(24.19)$ & $51.54(25.22)$ & $t_{(26)}=-0.270, p=0.789$ \\
\hline Thal A $\beta$ phase [52] & $\begin{array}{l}\text { Phase } 4, n=1 \\
\text { Phase } 5, n=18\end{array}$ & $\begin{array}{l}\text { Phase } 0, n=6 \text { Phase } 1, n=7 \text { Phase } 2, \\
\quad n=4 \text { Phase } 3, n=1 \\
\text { Phase } 4, n=3\end{array}$ & $\mathrm{U}_{(38)}=16.5, p=0.0001$ \\
\hline Braak NFT stage [8] & NFT stage V-VI, $n=19$ & $\begin{array}{l}\text { NFT stage } 0, n=1 \text { NFT stage I-II, } \\
n=8 \text { NFT stage III-IV, } n=12\end{array}$ & $\mathrm{U}_{(38)}=0.500, p=0.0001$ \\
\hline CERAD [35] & $\mathrm{C}, n=19$ & Negative, $n=16 \mathrm{~A}, n=3 \mathrm{~B}, n=2$ & \\
\hline NIA-AA [36] & High, $n=19$ & $\begin{array}{l}\text { No, } n=6 \\
\text { Low, } n=13 \text { Intermediate, } n=2\end{array}$ & \\
\hline McKeith criteria [32] & $\begin{array}{l}\text { No LBD, } n=15 \\
\text { Brainstem, } n=3 \\
\text { Amygdala predominant, } n=1\end{array}$ & $\begin{array}{l}\text { No LBD, } n=18 \\
\text { Brainstem, } n=3\end{array}$ & \\
\hline VCING criteria [49] & Low, $n=19$ & Low, $n=21$ & \\
\hline LATE-NC [20] & $\begin{array}{l}\text { Present, } n=13 \\
\text { Absent, } n=6\end{array}$ & $\begin{array}{l}\text { Present, } n=5 \\
\text { Absent, } n=16\end{array}$ & \\
\hline CAA score $[40]$ & $\begin{array}{l}\text { Stage } 0, n=3 \\
\text { Stage } 1, n=4 \\
\text { Stage } 2, n=5 \\
\text { Stage } 3, n=7 \\
\text { CapCAA absent, } n=14 \\
\text { CapCAA present, } n=5\end{array}$ & $\begin{array}{l}\text { Stage } 0, n=14 \\
\text { Stage } 1, n=1 \\
\text { Stage } 2, n=5 \\
\text { Stage } 3, n=1 \\
\text { CapCAA absent, } n=21\end{array}$ & \\
\hline WMLA $\%( \pm \mathrm{SD})$ & $27.92(21.52)$ & $27.24(17.37)$ & $t_{(38)}=-0.111, p=0.912$ \\
\hline $\mathrm{SI}( \pm \mathrm{SD})$ & $0.3(0.076)$ & $0.28(0.067)$ & $t_{(38)}=0.990, p=0.329$ \\
\hline AT8-IR $( \pm$ SD $)$ & $11.50(17.75)$ & $0.08(0.154)$ & $\mathrm{U}_{(38)}=8.5, p=0.0001$ \\
\hline 4G8-IR $( \pm \mathrm{SD})$ & $16.10(10.51)$ & $3.00(5.98)$ & $\mathrm{U}_{(38)}=29.00, p=0.0001$ \\
\hline NAWM BiA $( \pm S D)$ & $87.2(6.38)$ & $88.7(4.96)$ & $\mathrm{t}_{(38)}=0.794, p=0.433$ \\
\hline WML-BiA $( \pm \mathrm{SD})$ & $64.37(12.86)$ & $63.04(10.29)$ & $t_{(11)}=0.205, p=0.839$ \\
\hline NAWM LFB-IOD ( \pm SD) & 82.9E7 (8.81E7) & 81.7E7 (5.87E7) & $t_{(38)}=0.496, p=0.623$ \\
\hline WML LFB-IOD $( \pm$ SD $)$ & 77.4E7 (6.19E7) & 79.15E7 (5.73E7) & $t_{(11)}=0.891, p=0.378$ \\
\hline
\end{tabular}

$A D$, Alzheimer's disease; $d f$, degrees of freedom; $t$, Independent samples test; $F$, female; $M$, Male; $U$, Mann-Whitney $U$ test; PMD, post-mortem delay; $A \beta$, amyloid-beta; NFT, neurofibrillary tangle; CERAD, Consortium to Establish a Registry for Alzheimer's Disease; NIA-AA, National Institute on Ageing-Alzheimer's Association criteria for AD neuropathologic change; $L B$, Lewy body; VCING, vascular cognitive impairment neuropathological guidelines; LATE-NC, limbic-predominant age-related TDP-43 encephalopathy neuropathological change; $C A A$, cerebral amyloid angiopathy; $\operatorname{CapCAA}$, capillary CAA; $W M L A \%$, white matter lesion percentage area; SI, Sclerotic Index; IR, immunoreactivity

\section{Associations between WML severity and WML measures of axonal loss and demyelination}

Using Pearson's $(r)$ or Spearman's $(\rho)$ correlation coefficients, we examined the relationship between WML measures of axonal density (BiA) and myelin loss (LFB-IOD) adjusting for age; no significant association was revealed between $\mathrm{BiA}$ and LFB-IOD in either the $\mathrm{AD}(r=-0.375$, $p=0.084)$ or the control group $(r=-0.114, p=0.356)$. We then examined the relationship between WMLA and WML measures of BiA and LFB-IOD; regarding the whole cohort, WMLA negatively correlated with $\mathrm{BiA}(r=-0.386$, $p=0.019)$ and LFB-IOD $(r=0.541, p=0.001)$, indicating that increase WML severity was associated with increasing axonal loss and demyelination. However, when dichotomized based on diagnosis, WMLA in the control cases was only associated with LFB-IOD $(r=0.698, p=0.004$; Fig. 3a) and not $\mathrm{BiA}(p=0.079$; Fig. 3b), whereas WMLA in AD cases was associated with both LFB-IOD $(r=0.457$, $p=0.033$; Fig. 3a) and $\mathrm{BiA}(r=-0.479, p=0.031$; Fig. 3d). This indicates that WMLA seen in the control cases are primarily associated with demyelination and WMLA seen in $\mathrm{AD}$ cases are associated with both axonal and independent/ axonal loss-associated demyelination. 


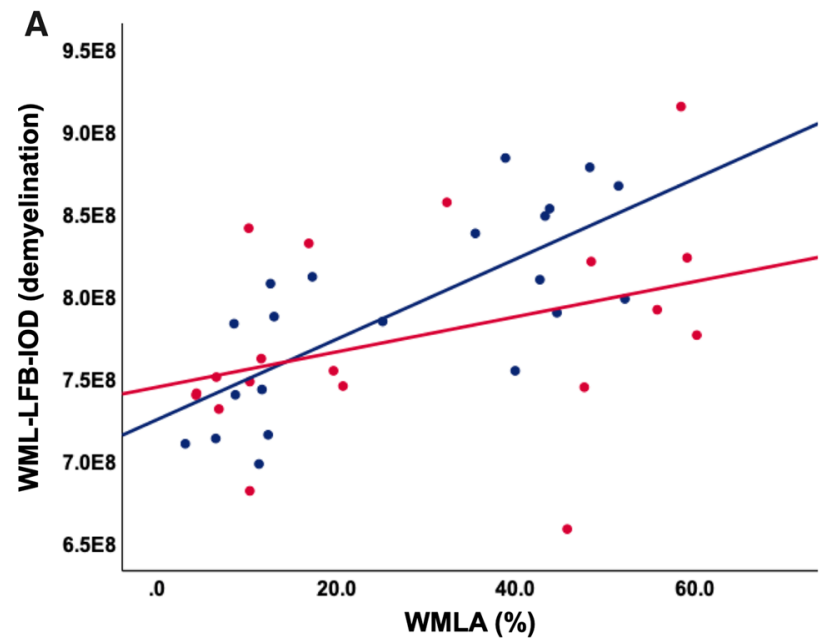

Fig. 3 Scatter graphs a A correlation between WMLA (i.e., white matter lesions severity) and WML-LFB-IOD (i.e., demyelination) was seen in both $\mathrm{AD}$ and control cases. b A negative correlation between WMLA and WML-BiA (axonal density) in AD cases only. $p$

\section{Influence of SVD, CAA, and cortical neurodegenerative pathology on WML severity axonal loss and demyelination}

We investigated whether cerebrovascular pathologies, i.e., SVD (SI) and CAA, and cortical AD pathologies, i.e., HP $\tau$ (AT8-IR) or A $\beta$ (4G8-IR) were associated with white matter pathological changes, i.e., WML severity (WMLA), axonal density (BiA), and myelin loss (LFB-IOD). In the AD group, SI was significantly associated with WMLA $(r=0.571, p=0.002)$ and LFB-IOD $(-0.597, p=0.009)$ but not $\mathrm{BiA}(p=0.103)$. In the controls, SI was also associated with WMLA $(r=0.648, p=0.001)$ and WML LFB-IOD $(r=0.707, p=0.003)$ and not WML-BiA $(p=0.206)$. CAA was not associated with WMLA, WML-BiA, or WML-LFBIOD in either the AD or control group $(p>0.408)$. Regarding cortical AD pathologies, only WML-BiA in the AD group was associated with AT8-IR $(\rho=0.432, p=0.037)$. No other association between AT8-IR and 4G8-IR were revealed with any variable in any group $(p>0.074)$.

Stepwise linear regression with pairwise deletion and controlled for age was used to investigate if the independent variables SI, CAA, AT8-IR, or 4G8-IR were predictors of dependent variables WMLA or WML-BiA and LFB-IOD measures. All stepwise regression data had a $\mathrm{VIF}<2$, indicating no collinearity, and is presented in Table 3. Briefly, regarding WML severity, i.e., WMLA, SI was found to be a significant predictor of WMLA in both the control $(\beta=0.644, p=0.002$; Table $3 \mathrm{a})$ and $\mathrm{AD}$ (; $\beta=0.505, p=0.027$; Table $3 \mathrm{~b}$ ) groups. Furthermore, in the AD group, a second model revealed frontal AT8-IR was also a significant predictor of WML when in the presence

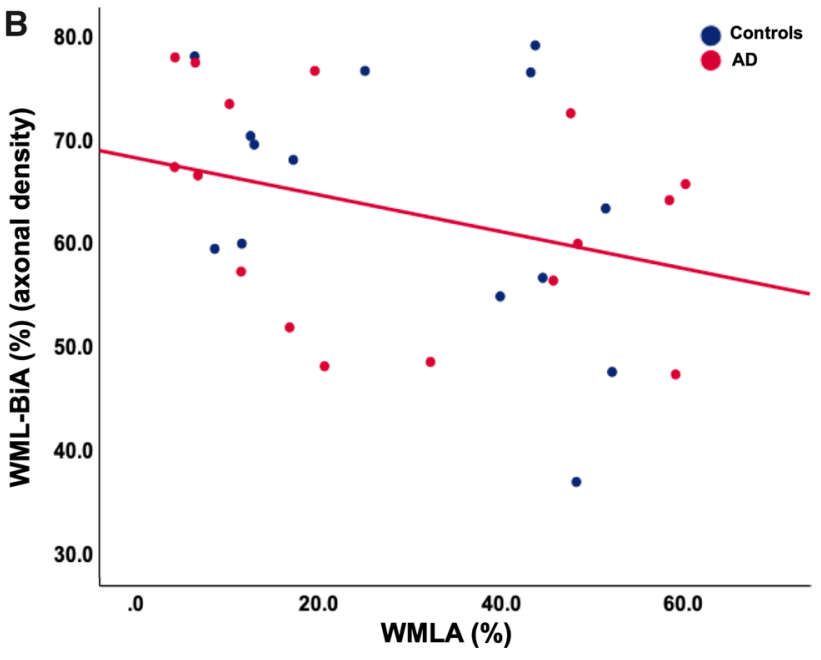

values and associated correlation coefficients are shown in main text. WML, white matter lesion; WMLA, white matter lesion area; LFBIOD, luxol fast blue integrated optical density (demyelination); BiA, Bielschowsky's area (axonal density decrease)

of SI (SI; $\beta=0.515, p=0.014$; AT $8 ; \beta=0.437, p=0.032$; Table $3 b$ ). Regarding demyelination, i.e., WML LFB-IOD, SI was found to be a significant predictor in both the control $(\beta=0.766, p=0.0001$; Table $3 \mathrm{c})$ and $\mathrm{AD}(\beta=0.544$, $p=0.016$; Table $3 \mathrm{~d}$ ) groups. No pathological variable was found to be a significant predictor of axonal density, i.e., WML-BiA (all models $p>0.249$ ).

\section{Wallerian degeneration and ischaemia in WML}

Regarding the Wallerian degeneration marker calpain2, no significant differences were seen in WML or NAWM measures between AD and controls ( $p>0.328$; Fig. $4 a)$. Furthermore, intragroup comparisons revealed no difference in calpain 2 measures between NAWM and WML (both AD and controls $p>0.503$; Fig. 4a). Regarding the ischaemia marker MAG:PLP, no significant differences were seen in WML or NAWM measures between AD and controls $(p>0.526$; Fig. 4b). Furthermore, intragroup comparisons revealed no difference in MAG:PLP measures between NAWM and WML (both AD and controls $p>0.087$; Fig. 4b). Finally, we examined correlations of WML measures of calpain2 and MAG:PLP with SI, CAA, AT8-IR, and 4G8-IR. In the control group, no pathological variable was associated with WMLcalpain2 ( $p>0.094)$ or WML-MAG:PLP $(p>0.084$; SI and WML-MAG:PLP, $p=0.084)$. In the AD group, WML-calpain-2 was associated with 4G8-IR only (rho 0.484; $p=0.047$; other variables $p>0.111$ ), and no associations were found between MAG:PLP and any pathological variables $(p>0.079)$. Stepwise linear regression, adjusted for age, was used to investigate if the independent variables SI, CAA, AT8-IR, or 4G8IR were predictors of dependent variables of WML-calpain2 
Table 3 Stepwise linear regression data for independent predictors of white matter lesions severity and demyelination

a

Controls

Dependent variable $=$ white matter lesion area

\begin{tabular}{llll}
\hline Model 1 summary & $R^{2}$ & SE & $F_{(2)}$ \\
& 0.415 & 13.63 & 13.487 \\
Independent variables & Standardized coefficients- $\beta$ & $p$ value & 0.002 \\
SI & 0.644 & 0.002 \\
CAA & - & 0.994 \\
AT8-IR & - & 0.945 \\
4G8-IR & - & 0.995 & \\
Age & - & 1.000 & \\
\hline
\end{tabular}

b

$\mathrm{AD}$

Dependent variable $=$ white matter lesion area

\begin{tabular}{|c|c|c|c|c|}
\hline Model 1 summary & $R^{2}$ & SE & $F_{(2)}$ & $p$ value \\
\hline & 0.255 & 19.11 & 5.821 & 0.027 \\
\hline Independent variables & Standardized coefficients $-\beta$ & $p$ value & & \\
\hline SI & 0.505 & 0.027 & & \\
\hline CAA & - & 0.981 & & \\
\hline AT8-IR & - & 0.999 & & \\
\hline 4G8-IR & - & 0.997 & & \\
\hline Age & - & 0.892 & & \\
\hline \multirow[t]{2}{*}{ Model 2 summary } & $R^{2}$ & SE & $F_{(2)}$ & $p$ value \\
\hline & 0.446 & 16.98 & 6.444 & 0.009 \\
\hline Independent variables & Standardized coefficients $-\beta$ & $p$ value & & \\
\hline SI & 0.515 & 0.014 & & \\
\hline CAA & - & 0.881 & & \\
\hline AT8-IR & 0.437 & 0.032 & & \\
\hline 4G8-IR & - & 0.996 & & \\
\hline Age & - & 0.685 & & \\
\hline
\end{tabular}

$\mathrm{c}$

Controls

Dependent variable $=$ demyelination

\begin{tabular}{llll}
\hline Model 1 summary & $R^{2}$ & SE & $F_{(2)}$ \\
\hline \\
Independent variables & 0.587 & 37.77 E6 & 27.026 \\
SI & Standardized coefficients- $\beta$ & $p$ value & 0.0001 \\
CAA & 0.766 & 0.0001 & \\
AT8-IR & - & 0.994 \\
4G8-IR & - & 0.944 \\
Age & - & 0.995 & 1.000 \\
\hline
\end{tabular}

d

$\mathrm{AD}$

Dependent variable $=$ demyelination

\begin{tabular}{lllll}
\hline Model 1 summary & $R^{2}$ & SE & $F_{(2)}$ & $p$ value \\
\hline & 0.295 & $53.50 \mathrm{E} 6$ & 7.129 & 0.016 \\
\hline
\end{tabular}


Table 3 (continued)

d

$\mathrm{AD}$

Dependent variable $=$ demyelination

\begin{tabular}{llll}
\hline Model 1 summary & $R^{2}$ & SE & $F_{(2)}$ \\
\hline Independent variables & Standardized coefficients- $\beta$ & $p$ value \\
SI & 0.544 & 0.016 \\
CAA & - & 0.981 \\
AT8-IR & - & 0.999 \\
4G8-IR & - & 0.997 \\
Age & - & 0.892 \\
\hline
\end{tabular}

$S E$, standard error; SI, Sclerotic Index; $C A A$, cerebral amyloid angiopathy; $I R$, immunoreactivity; $A D$, Alzheimer's disease

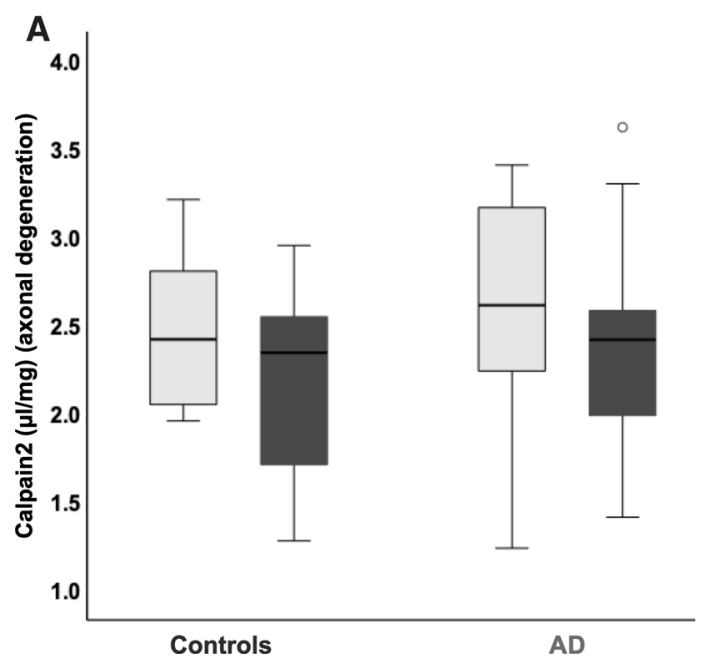

Fig. 4 Box plots; a No significant differences were revealed in calpain2 measures between $\mathrm{AD}$ and controls nor between WML and NAWM measures within groups. No significant differences were revealed in MAG:PLP measures between $\mathrm{AD}$ and controls nor

or WML-MAG:PLP; no model was revealed in the AD or control for any dependent variables (all models $p>0.141$ ).

\section{Discussion}

In this pilot study, we reveal for the first time in human post-mortem tissue that the aetiology of frontal WML in AD is possibly the result of both SVD-associated mechanisms and degenerative changes secondary to the accumulation of AD pathology. This current data suggest a contrasting aetiology to WML in the parietal lobe of the same cohort that was primarily associated with degenerative changes, as described in our previous findings in McAleese et al. [30]. Combined with our previous
B

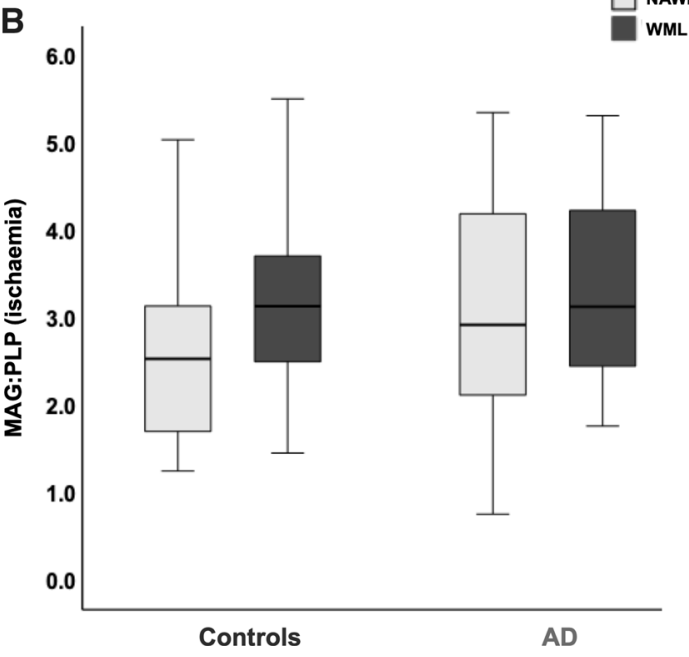

between WML and NAWM measures within groups. $p$ values are shown in main text. $A D$, Alzheimer's disease; $M A G$, myelin-associated glycoprotein; $P L P$, proteolipid protein

findings, our current data reveal that regional differences in the aetiology of WML in AD with posterior WML possibly associated with degenerative mechanisms secondary to AD pathology, while anterior changes can be associated with both SVD and degenerative associated mechanisms.

It has been previously shown that parietal WML as seen in $\mathrm{AD}$ can occur as a consequence of degenerative axonal loss secondary to AD pathology in addition to SVD-associated white matter changes. Regional variation in the pathogenesis of white matter changes has been indicated using neuroimaging, but has not been investigated using human post-mortem tissue. We reveal that frontal WML as seen in individuals with AD are associated with SVD as indicated by arteriolosclerosis being associated with and a significant predictor of WML severity. This is in contrast to 
our previous findings in the parietal WM, where WML are associated with cortical neurodegenerative pathology but not SVD [30]. SVD was also associated with and a predictor of WML severity in the non-demented control group in agreement with the findings from the parietal region of the same cohort [30]. This striking difference between the anterior and posterior regions indicates that SVD perhaps has a more prominent influence on the development of frontal WML but not parietal WML in both AD and non-demented controls. WMH volume is associated with increased vascular risk [58] with the frontal white matter particular vulnerable to CVRF, i.e., hypercholesterolemia [43] and hypertension $[18,44]$ and vascular insults. This maybe due to the frontal WM blood supply being from the territories of the distal branches of the superficial perforating arteries of the anterior and middle cerebral arteries, which are prone to the development of SVD

The underlying pathomechanisms of white matter changes in $\mathrm{AD}$ are still poorly understood and heterogeneous, comprising of a complex interface between neurodegeneration and vascular dysfunction. Although the causal effects are still elucidated, it is thought that cerebral hypoperfusion as a result of CVRF can lead to critical dysfunction of the neurovascular unit, BBB exchange, and clearance pathways, which can then leave the brain vulnerable to developing, or synergistically influencing, the development of concomitant neurodegenerative disease, ischaemia, and neuroinflammation [45]. Interestingly, we found no increase in the biochemical markers of ischaemia (MAG:PLP) in white matter lesion tissue compared to normal white matter, and only a trend was revealed between increasing arteriolosclerosis severity and ischaemia. This was surprising given that arteriolosclerosis, and in general SVD, is associated and a predictor of WML and is thought to be an ischaemia driven mechanism. This lack of difference in ischaemia may be due to the underpowering of the study, given that a previous study has found a strong association between MAG:PLP and arteriolosclerosis and SVD severity in two separate cohorts [5]. However, it is important to note that ischaemia in SVD can be a later event, especially when there is no concomitant CVD and/or disrupted cerebral blood flow. Earlier stage vascular dysfunction at the cellular level, i.e., BBB breakdown, perivascular leakage, endothelial dysfunction, and an impaired neurovascular unit, may result in white matter tissue damage before the onset of significant ischaemia, and therefore, these data might reflect an earlier stage of disease that is not yet primarily ischaemic (for a full review please see [55]).

However, this study also revealed evidence of a degenerative influence on the aetiology of frontal WML in AD. In the AD group, increasing severity of WML was associated with both axonal loss and trended with demyelination, in contrast to the non-demented control group in which WML were predominantly associated with demyelination only. This is reflective of the pathological composition of WML in the parietal region of the same cohort as shown in our previous study [30]. In addition, a correlation was revealed between calpain levels and $A \beta$ pathology, possibly indicating an increase in calpain activation with progression of $\mathrm{AD}$. The influence of AD-associated white matter changes has been previously indicated in neuroimaging data; increased $\mathrm{A} \beta$ pathology, as detected via PET or CSF, is associated with frontal WMH independent of tau PET [16, 54]. Furthermore, individuals with autosomal dominant $\mathrm{AD}$, who are below the age of onset for major CVRF, indicate early global, inclusive of specific frontal, white matter changes that are associated with increased p-tau and decreased A $\beta$ 1-42 levels in CSF samples [2]. A key finding of the degenerative influence in the frontal region of $\mathrm{AD}$ cases is that $\mathrm{HP} \tau$ was only a significant predictor of WML severity when in the presence of SVD, therefore, indicating that the possible influence of $\mathrm{HP} \tau$-associated degenerative axonal loss is in addition to and secondary to the independent influence of SVD. This finding is in agreement with a previous neuroimaging study which indicated to regional differences in periventricular white matter hyperintensities between non-demented controls and AD due to an additive effect of vascular and neurodegenerative injuries [58].

One may speculate that these data are reflective of the 'two-hit vascular hypothesis' of AD that states a first initial insult or 'hit' from cerebrovascular damage, such as chronic hypoperfusion from SVD, is sufficient to initiate neuronal injury, which are subsequently more vulnerable to a second 'hit' from independent AD-pathology insults, e.g., accumulation of $\mathrm{A} \beta$ and $\mathrm{HP} \tau$ pathology [39].

The topographical progression of $\mathrm{HP} \tau$ pathology in $\mathrm{AD}$ reaches the frontal cortices in the later stages of the disease progression, requiring a longer time frame for a degenerative influence to become prominent, compared to the more localised parietal white matter that has direct white matter projections with the hippocampal and entorhinal subfields. Finally, lack of an increase in WML measures of calpain in the $\mathrm{AD}$ group indicates no significant upregulation of Wallerian degeneration, in contrast to the significant increase seen in AD WML tissue from the parietal region [30], further suggesting that significant degenerative insults occur after vascular insults. Therefore, SVD-associated mechanisms appear to exert a significant impact to the frontal white matter, compared to the parietal white matter, resulting in the regional aetiological differences. This highlights the importance of early intervention regarding CVRF and the consideration of vasculoprotective treatments.

Unexpectedly, no associations were seen between CAA and frontal WMH. White matter changes in both sporadic AD-associated CAA [11,37] and familial APP mutations [57] have indicated an increase in frontal WMH 
burden, indicating that the co-existence of CAA in $\mathrm{AD}$ may increase the burden of WMH. Given the likely mixed aetiology of frontal WMH and that CAA represents an interface between cerebrovascular disease and neurodegenerative pathology, an association with CAA was speculated. Although CAA primarily affects the leptomeningeal and cortical vessels of the neocortical regions and somewhat resembles the distribution pattern of $\mathrm{A} \beta$ pathology, the occipital lobe is frequently and severely affected first before progressing rostrally [3]. A lack of relationship may reflect that CAA was not as severe in the frontal region of this cohort and the use of semi-quantitative assessment, in comparison to quantitative methods used for the other neuropathologies may not have been sufficient to reveal any associations with white matter changes. Use of advancing artificial intelligence systems for the quantification of CAA in future studies is warranted.

The pathological findings and suggestions from this current data and our previous study [30] regarding the regional specific pathogenesis of WML in AD are consistent with neuroimaging findings from Lee et al., which indicated regional aetiological differences in microstructural disruption of the CC [25]. Lee and colleagues indicate that both vascular and $\mathrm{AD}$-associated degenerative mechanisms contributed to anterior $\mathrm{CC}$ white matter disruption which is in line with our data from this study of a mixed pathogenic model of frontal WMH development with the contribution of both SVD (primarily) and a later addition of AD-associated degenerative mechanisms. In contrast, Lee and colleagues demonstrate that posterior $\mathrm{CC}$ white matter disruption was primarily driven by $\mathrm{AD}$-associated degeneration and not vascular mechanisms which is in agreement with our previous findings that parietal WML in AD are more likely associated with degenerative axonal changes secondary to cortical AD pathology and not SVD [30].

Understanding the various underlying pathogenic mechanisms of white matter changes and their regional differences is crucial for the accurate diagnosis and therapeutic interventions of patients with cognitive impairment. During life, white matter changes are detected as $\mathrm{WMH}$ and often interpreted as a surrogate marker for general SVD [13, 15], and, although the presence of white matter change is indicated, imaging changes are unable to determine the specific SVD-associated pathology or an alternative mechanism, i.e., degenerative axonal loss. Hence, elucidating and understanding the underlying pathology and associated mechanisms that underline identical WMH signatures are crucial. This study did not directly map WMH and with regions of pathology, and therefore, the proposed concept is speculative and warrants future confirmative direct radiological-neuropathological studies. It is crucial that location, severity, and progression gradient of WMH burden are taken into consideration when interpretating white matter changes, especially given the use of WMH as a surrogate biomarker for SVD which may result in the misdiagnosis of patients, bias cohort stratification in clinical trials, and have a detrimental impact on therapeutic interventions for patients.

One important limitation of this study is the modest dataset and possible under powering; due to the use of a consecutive series not all cases contained a WML, therefore, reducing the case numbers for statistical analysis. We employed pairwise deletion in the analysis to optimise the data available, but results should be interpreted as tentative, and a larger follow-up study for validation is encouraged. In additional, we are aware that the analysis has not taking into consideration important CVRF and CVD covariates i.e., blood pressure, presence of diabetes, hyperlipidaemia, hypercholesterolaemia, smoking, etc. We acknowledge that these factors, particularly hypertension, can influence the development and progression of both white matter changes and specifically arteriolosclerosis and lipohyalinosis [22, 24]; however, these data were unavailable or insufficient for analysis.

In conclusion, this preliminary study tentatively suggests that in individuals with AD, both SVD-associated mechanisms and cortical AD-associated degenerative pathology have influences on the development of frontal WML in contrast to parietal WML that appear to be more likely associated with $\mathrm{AD}$-associated degenerative mechanisms.

Supplementary Information The online version contains supplementary material available at https://doi.org/10.1007/s00401-021-02376-2.

Acknowledgements We thank Mrs Debbie Lett for her assistance with clinical data collection. We are very grateful to the individuals who kindly donated their brains to the Newcastle Brain Tissue Resource.

Funding The research was supported by the Alzheimer's Society (Grant number: AS-JF-18-01). Tissue for this study was provided by the Newcastle Brain Tissue Resource, which is funded in part by a grant from the UK Medical Research Council (G0400074) and by Brains for Dementia research, a joint venture between Alzheimer's Society and Alzheimer's Research UK.

\section{Declarations}

Conflict of interest The authors declare that they have no conflict of interest.

Open Access This article is licensed under a Creative Commons Attribution 4.0 International License, which permits use, sharing, adaptation, distribution and reproduction in any medium or format, as long as you give appropriate credit to the original author(s) and the source, provide a link to the Creative Commons licence, and indicate if changes were made. The images or other third party material in this article are included in the article's Creative Commons licence, unless indicated otherwise in a credit line to the material. If material is not included in the article's Creative Commons licence and your intended use is not permitted by statutory regulation or exceeds the permitted use, you will need to obtain permission directly from the copyright holder. To view a copy of this licence, visit http://creativecommons.org/licenses/by/4.0/. 


\section{References}

1. Alosco ML, Sugarman MA, Besser LM, Tripodis Y, Martin B, Palmisano JN et al (2018) A Clinicopathological investigation of white matter hyperintensities and alzheimer's disease neuropathology. J Alzheimers Dis 63:1347-1360

2. Araque Caballero MA, Suarez-Calvet M, Duering M, Franzmeier N, Benzinger T, Fagan AM et al (2018) White matter diffusion alterations precede symptom onset in autosomal dominant Alzheimer's disease. Brain 141:3065-3080

3. Attems J, Jellinger KA, Lintner F (2005) Alzheimer's disease pathology influences severity and topographical distribution of cerebral amyloid angiopathy. Acta Neuropathol 110:222-231

4. Barber R, Scheltens P, Gholkar A, Ballard C, McKeith I, Ince P et al (1999) White matter lesions on magnetic resonance imaging in dementia with Lewy bodies, Alzheimer's disease, vascular dementia, and normal aging. J Neurol Neurosurg Psychiatry 67:66-72

5. Barker R, Wellington D, Esiri MM, Love S (2013) Assessing white matter ischemic damage in dementia patients by measurement of myelin proteins. J Cereb Blood Flow Metab 33:1050-1057

6. Bosch B, Arenaza-Urquijo EM, Rami L, Sala-Llonch R, Junque C, Sole-Padulles C et al (2012) Multiple DTI index analysis in normal aging, amnestic MCI and AD. Relationship with neuropsychological performance. Neurobiol Aging 33:61-74

7. Braak H, Del Tredici K, Rub U, de Vos RA, Jansen Steur EN, Braak E (2003) Staging of brain pathology related to sporadic Parkinson's disease. Neurobiol Aging 24:197-211

8. Braak H, Alafuzoff I, Arzberger T, Kretzschmar H, Del Tredici K (2006) Staging of Alzheimer disease-associated neurofibrillary pathology using paraffin sections and immunocytochemistry. Acta Neuropathol 112:389-404

9. Brickman AM, Tosto G, Gutierrez J, Andrews H, Gu Y, Narkhede A et al (2018) An MRI measure of degenerative and cerebrovascular pathology in Alzheimer disease. Neurology 91:e1402-e1412

10. Brun A, Englund E (1986) A white matter disorder in dementia of the Alzheimer type: a pathoanatomical study. Ann Neurol 19:253-262

11. Charidimou A, Gang Q, Werring DJ (2012) Sporadic cerebral amyloid angiopathy revisited: recent insights into pathophysiology and clinical spectrum. J Neurol Neurosurg Psychiatry 83:124-137

12. Coleman M (2005) Axon degeneration mechanisms: commonality amid diversity. Nat Rev Neurosci 6:889-898

13. Dubois B, Feldman HH, Jacova C, Hampel H, Molinuevo JL, Blennow K et al (2014) Advancing research diagnostic criteria for Alzheimer's disease: the IWG-2 criteria. Lancet Neurol 13:614-629

14. Englund E, Brun A, Alling C (1988) White matter changes in dementia of Alzheimer's type. Biochem Neuropathol Corr Brain 111(Pt 6):1425-1439

15. Gorelick PB, Scuteri A, Black SE, Decarli C, Greenberg SM, Iadecola $C$ et al (2011) Vascular contributions to cognitive impairment and dementia: a statement for healthcare professionals from the American Heart Association/American Stroke Association. Stroke 42:2672-2713

16. Graff-Radford J, Arenaza-Urquijo EM, Knopman DS, Schwarz CG, Brown RD, Rabinstein AA et al (2019) White matter hyperintensities: relationship to amyloid and tau burden. Brain 142:2483-2491

17. Grinberg LT, Thal DR (2010) Vascular pathology in the aged human brain. Acta Neuropathol 119:277-290

18. Habes M, Sotiras A, Erus G, Toledo JB, Janowitz D, Wolk DA et al (2018) White matter lesions: Spatial heterogeneity, links to risk factors, cognition, genetics, and atrophy. Neurology 91:e964-e975

19. Hachinski VC, Potter P, Merskey H (1987) Leuko-araiosis. Arch Neurol 44:21-23

20. Josephs KA, Murray ME, Whitwell JL, Parisi JE, Petrucelli L, Jack CR et al (2014) Staging TDP-43 pathology in Alzheimer's disease. Acta Neuropathol 127:441-450

21. Kantarci K, Murray ME, Schwarz CG, Reid RI, Przybelski SA, Lesnick T et al (2017) White-matter integrity on DTI and the pathologic staging of Alzheimer's disease. Neurobiol Aging 56:172-179

22. Khan U, Porteous L, Hassan A, Markus HS (2007) Risk factor profile of cerebral small vessel disease and its subtypes. J Neurol Neurosurg Psychiatry 78:702-706

23. Lammie GA, Brannan F, Slattery J, Warlow C (1997) Nonhypertensive cerebral small-vessel disease. An autopsy study. Stroke 28:2222-2229

24. Lammie GA (2002) Hypertensive cerebral small vessel disease and stroke. Brain Pathol 12:358-370

25. Lee DY, Fletcher E, Martinez O, Zozulya N, Kim J, Tran J et al (2010) Vascular and degenerative processes differentially affect regional interhemispheric connections in normal aging, mild cognitive impairment, and Alzheimer disease. Stroke 41:1791-1797

26. Leys D, Pruvo JP, Parent M, Vermersch P, Soetaert G, Steinling $M$ et al (1991) Could Wallerian degeneration contribute to "leuko-araiosis" in subjects free of any vascular disorder? J Neurol Neurosurg Psychiatry 54:46-50

27. Litchfield S, Nagy Z (2001) New temperature modification makes the Bielschowsky silver stain reproducible. Acta Neuropathol 101:17-21

28. Ma M, Ferguson TA, Schoch KM, Li J, Qian Y, Shofer FS et al (2013) Calpains mediate axonal cytoskeleton disintegration during Wallerian degeneration. Neurobiol Dis 56:34-46

29. McAleese KE, Firbank M, Dey M, Colloby SJ, Walker L, Johnson $\mathrm{M}$ et al (2015) Cortical tau load is associated with white matter hyperintensities. Acta Neuropathol Commun 3:60

30. McAleese KE, Walker L, Graham S, Moya ELJ, Johnson M, Erskine D et al (2017) Parietal white matter lesions in Alzheimer's disease are associated with cortical neurodegenerative pathology, but not with small vessel disease. Acta Neuropathol 134:459-473

31. McCreary CR, Beaudin AE, Subotic A, Zwiers AM, Alvarez A, Charlton A et al (2020) Cross-sectional and longitudinal differences in peak skeletonized white matter mean diffusivity in cerebral amyloid angiopathy. Neuroimage Clin 27:102280

32. McKeith IG, Dickson DW, Lowe J, Emre M, O’Brien JT, Feldman $\mathrm{H}$ et al (2005) Diagnosis and management of dementia with Lewy bodies: third report of the DLB Consortium. Neurology 65:1863-1872

33. McKhann G, Drachman D, Folstein M, Katzman R, Price D, Stadlan EM (1984) Clinical diagnosis of Alzheimer's disease: report of the NINCDS-ADRDA Work Group under the auspices of Department of Health and Human Services Task Force on Alzheimer's Disease. Neurology 34:939-944

34. McKhann GM, Knopman DS, Chertkow H, Hyman BT, Jack CR $\mathrm{Jr}$, Kawas CH et al (2011) The diagnosis of dementia due to Alzheimer's disease: recommendations from the National Institute on Aging-Alzheimer's Association workgroups on diagnostic guidelines for Alzheimer's disease. Alzheimers Dement 7:263-269

35. Mirra SS, Heyman A, McKeel D, Sumi SM, Crain BJ, Brownlee LM et al (1991) The consortium to establish a registry for Alzheimer's Disease (CERAD). Part II. Standardization of the neuropathologic assessment of Alzheimer's disease. Neurology 41:479-486 
36. Montine TJ, Phelps CH, Beach TG, Bigio EH, Cairns NJ, Dickson DW et al (2012) National institute on aging-Alzheimer's association guidelines for the neuropathologic assessment of Alzheimer's disease: a practical approach. Acta Neuropathol 123:1-11

37. Moscoso A, Rey-Bretal D, Silva-Rodriguez J, Aldrey JM, Cortes J, Pias-Peleteiro J et al (2020) White matter hyperintensities are associated with subthreshold amyloid accumulation. Neuroimage 218:116944

38. Nasrabady SE, Rizvi B, Goldman JE, Brickman AM (2018) White matter changes in Alzheimer's disease: a focus on myelin and oligodendrocytes. Acta Neuropathol Commun 6:22

39. Nelson AR, Sweeney MD, Sagare AP, Zlokovic BV (2016) Neurovascular dysfunction and neurodegeneration in dementia and Alzheimer's disease. Biochim Biophys Acta 1862:887-900

40. Olichney JM, Ellis RJ, Katzman R, Sabbagh MN, Hansen L (1997) Types of cerebrovascular lesions associated with severe cerebral amyloid angiopathy in Alzheimer's disease. Ann N Y Acad Sci 826:493-497

41. Pantoni L, Garcia JH, Gutierrez JA (1996) Cerebral white matter is highly vulnerable to ischemia. Stroke 27:1641-1646 (discussion 1647)

42. Pantoni L, Gorelick PB (2014) Cerebral small vessel disease. Cambridge Univeristy Press, Cambridge

43. Rostrup E, Gouw AA, Vrenken H, van Straaten EC, Ropele S, Pantoni L et al (2012) The spatial distribution of age-related white matter changes as a function of vascular risk factors-results from the LADIS study. Neuroimage 60:1597-1607

44. Salvado G, Brugulat-Serrat A, Sudre CH, Grau-Rivera O, SuarezCalvet M, Falcon C et al (2019) Spatial patterns of white matter hyperintensities associated with Alzheimer's disease risk factors in a cognitively healthy middle-aged cohort. Alzheimers Res Ther 11:12

45. Scheffer S, Hermkens DMA, van der Weerd L, de Vries HE, Daemen M (2021) Vascular hypothesis of Alzheimer disease: topical review of mouse models. Arterioscler Thromb Vasc Biol 41:1265-1283

46. Schmidt R, Lechner H, Fazekas F, Niederkorn K, Reinhart B, Grieshofer P et al (1994) Assessment of cerebrovascular risk profiles in healthy persons: definition of research goals and the Austrian Stroke Prevention Study (ASPS). Neuroepidemiology 13:308-313

47. Schmidt R, Enzinger C, Ropele S, Schmidt H, Fazekas F (2003) Progression of cerebral white matter lesions: 6-year results of the Austrian Stroke Prevention Study. Lancet 361:2046-2048

48. Scott JA, Braskie MN, Tosun D, Maillard P, Thompson PM, Weiner M et al (2016) Cerebral amyloid is associated with greater white-matter hyperintensity accrual in cognitively normal older adults. Neurobiol Aging 48:48-52

49. Skrobot OA, Attems J, Esiri M, Hortobagyi T, Ironside JW, Kalaria RN et al (2016) Vascular cognitive impairment neuropathology guidelines (VCING): the contribution of cerebrovascular pathology to cognitive impairment. Brain 139:2957-2969

50. Smallwood A, Oulhaj A, Joachim C, Christie S, Sloan C, Smith AD et al (2012) Cerebral subcortical small vessel disease and its relation to cognition in elderly subjects: a pathological study in the Oxford Project to Investigate Memory and Ageing (OPTIMA) cohort. Neuropathol Appl Neurobiol 38:337-343

51. Strain JF, Smith RX, Beaumont H, Roe CM, Gordon BA, Mishra $S$ et al (2018) Loss of white matter integrity reflects tau accumulation in Alzheimer disease defined regions. Neurology 91:e313-e318

52. Thal DR, Rub U, Orantes M, Braak H (2002) Phases of A betadeposition in the human brain and its relevance for the development of AD. Neurology 58:1791-1800

53. Tian J, Shi J, Bailey K, Mann DM (2004) Relationships between arteriosclerosis, cerebral amyloid angiopathy and myelin loss from cerebral cortical white matter in Alzheimer's disease. Neuropathol Appl Neurobiol 30:46-56

54. Walsh P, Sudre CH, Fiford CM, Ryan NS, Lashley T, Frost C et al (2020) CSF amyloid is a consistent predictor of white matter hyperintensities across the disease course from aging to Alzheimer's disease. Neurobiol Aging 91:5-14

55. Wardlaw JM, Smith C, Dichgans M (2019) Small vessel disease: mechanisms and clinical implications. Lancet Neurol 18:684-696

56. Yamamoto Y, Ihara M, Tham C, Low RW, Slade JY, Moss T et al (2009) Neuropathological correlates of temporal pole white matter hyperintensities in CADASIL. Stroke 40:2004-2011

57. Yang Y, Ye XB, Chen H, Zhong YF, Zhang QW, Hu XY et al (2020) An APP mutation family exhibiting white matter hyperintensities and cortical calcification in East China. Neurol Sci 41:2921-2928

58. Yoshita M, Fletcher E, Harvey D, Ortega M, Martinez O, Mungas DM et al (2006) Extent and distribution of white matter hyperintensities in normal aging, MCI, and AD. Neurology 67:2192-2198

Publisher's Note Springer Nature remains neutral with regard to jurisdictional claims in published maps and institutional affiliations. 